\title{
Bio-inspired silver selenide nano-chalcogens using aqueous extract of Melilotus officinalis with biological activities
}

\author{
Seyedeh Zahra Mirzaei ${ }^{1}$, Hamed Esmaeil Lashgarian², Maryam Karkhane², Kiana Shahzamani ${ }^{3}$, \\ Alaa Kamil Alhameedawi ${ }^{4}$ and Abdolrazagh Marzban ${ }^{1 *}$ (I)
}

\begin{abstract}
For the first time, an aqueous extract of Melilotus officinalis was used to synthesize bimetallic silver selenide chalcogenide nanostructures ( $\mathrm{Ag}_{2} \mathrm{Se}-\mathrm{NCS}$ ). The formation of NCs was confirmed and characterized by UV-visible and FTIR spectroscopy, SEM and TEM imaging, XRD and EDX crystallography, zeta potential (ZP) and size distribution (DLS). The bioactivities of biosynthesized $\mathrm{Ag}_{2} \mathrm{Se}-\mathrm{NCs}$, such as antibacterial, antibiofilm, antioxidant and cytotoxicity potentials, were then examined. Bio-based $\mathrm{Ag}_{2} \mathrm{Se}-\mathrm{NCs}$ were successfully synthesized with mostly spherical shape in the size range of 20-40 nm. Additionally, the MIC and MBC values of $\mathrm{Ag}_{2} \mathrm{Se}-\mathrm{NC}$ s against $\beta$-lactam-resistant Pseudomonas aeruginosa (ATCC 27853) were 3.12 and $50 \mu \mathrm{g} / \mathrm{ml}$, respectively. The DPPH scavenging potential of $\mathrm{Ag}_{2} \mathrm{Se}-\mathrm{NCs}$ in terms of $\mathrm{IC}_{50}$ was estimated to be 58.52. Green-synthesized $\mathrm{Ag}_{2} \mathrm{Se}-\mathrm{NCs}$ have been shown to have promising benefits and could be used for biomedical applications. Although the findings indicate promising bioactivity of $\mathrm{Ag}_{2} \mathrm{Se}-\mathrm{NC}$ s synthesized by $M$. officinalis extract $(M O)$, more studies are required to clarify the comprehensive mechanistic biological activities.
\end{abstract}

Keywords: Silver selenide nano-chalcogens ( $\mathrm{Ag}_{2} \mathrm{Se}-\mathrm{NCS}$ ), Melilotus officinalis, Pseudomonas aeruginosa, Biological activities

\section{Introduction}

Silver chalcogenides, particularly $\mathrm{Ag}_{2} \mathrm{Se}$, are semiconductors with impressive physicochemical properties being used in electronics, optical conductors, infrared detectors, electromagnetic field sensors and optical filters. A variety of studies have examined the different properties of $\mathrm{Ag}_{2} \mathrm{Se}$ on the scale of microstructures, nanostructures, quantum dots and bulk forms (Martinez-Nuñez et al. 2016; Vo et al. 2016). $\mathrm{Ag}_{2} \mathrm{Se}$ nanostructures, in particular quantum dots, have unique properties that make them suitable for bioimaging (Yang et al. 2018). Generally, $\mathrm{Ag}_{2} \mathrm{Se}-\mathrm{NCs}$ can be synthesized in two distinct crystalline phases. Orthorhombic crystalline phase $\left(\beta-\mathrm{Ag}_{2} \mathrm{Se}\right)$

\footnotetext{
${ }^{*}$ Correspondence: marzban86@gmail.com

${ }^{1}$ Razi Herbal Medicines Research Center, Lorestan University of Medical

Sciences, P.O. Box: 6816889468, Khorramabad, Iran

Full list of author information is available at the end of the article
}

have photocatalytic and fluorescence-emitting activities used in the manufacture of optical sensors and light-sensitive films. In contrast, the body-centered cubic phase $\left(\alpha-\mathrm{Ag}_{2} \mathrm{Se}\right)$ is a metallic structure with electrolyte properties mainly used to manufacture batteries (Ayele 2016).

The most common processes, including high-temperature synthesis, microwave irradiation, electrochemical method and sonochemical reaction, have been developed for the synthesis of $\mathrm{Ag}_{2} \mathrm{Se}-\mathrm{NCs}$ (Jafari et al. 2013). These techniques have limitations due to the use of chemical reagents, various solvents and increased energy consumption. Many researchers have also attempted alternative and more accessible approaches to achieve $\mathrm{Ag}_{2} \mathrm{Se}$ nano-chalcogenides (Ayele 2016; Gholami et al. 2018; Sibiya and Moloto 2017; Yang et al 2018).

Several different approaches have been established for the use of bioactive compounds for nanoparticles (NPs) synthesis (Gilavand et al. 2021). Biological processes 
using natural reactants such as plant metabolites and microorganisms have been found cheaper and more reliable. However, NPs are inherently unstable due to an increased van der Waals force on their surface that tends to aggregate (Liu et al. 2018). In this regard, biologically active metabolites such as polyphenols, flavonoids, terpenoids and biopolymers such as nucleic acids, lipids and proteins are excellent capping agents that prevent them from accumulating as well as preventing their uncontrolled growth (Dobrucka 2020).

One of the most important applications of biosynthesized NPs is the development and design of pharmaceutical formulations. Since the antimicrobial potential of NPs is well established, it can be an attractive strategy for controlling bacterial, fungal, viral and parasitic infections ( $\mathrm{Lu}$ et al. 2020). On the other hand, new antimicrobial drugs are required due to the advent of microbial resistance. $M$. officinalis is a medicinal plant with extensive therapeutic properties. Several metabolites of M. officinalis with remarkable biological activities are found that could be used for bioreduction of metal in the nanoparticle synthesis. According to the studies, some major bioactive compounds are coumarins derivatives, hydroxycinnamic glucosides, phenolic acids, $p$-hydroxybenzoic acid, chlorogenic acid, vanillic acid, caffeic acid, salicylic acid, ferulic acid and ellagic acid (Anthony 2009; Kanipandian and Thirumurugan 2014; Mirzaei et al. 2020). Although various properties of $\mathrm{Ag}_{2} \mathrm{Se}-\mathrm{NCs}$ have been reported, their biological properties have not been studied by researchers (Gopinath et al. 2013; Liu et al 2018; Sibiya and Moloto 2017). In this study, an aqueous extract of $M$. officinalis ( $M O$ extract) was used as a reducing and capping agent for the synthesis of $\mathrm{Ag}_{2} \mathrm{Se}-\mathrm{NCs}$. After that, the antibiofilm, antibacterial, antioxidant and cytotoxicity properties of biosynthesized NCs were investigated.

\section{Materials and methods \\ Materials and reagents}

All materials were provided from Sigma chemical company (St. Louis, MO). Microbial culture media were purchased from Himedia (Mumbai, India). Human hepatocellular carcinoma, HepG2 (ATCC HB-8065) cell line was prepared from the cell collection bank of the Pasteur Institute of Iran. The bacterial strain, Pseudomonas aeruginosa (ATCC 27853) was procured from the IROST microbial culture collection (Tehran, Iran).

\section{Aqueous extraction and phytochemical analyses} Aqueous extract preparation and flavonoid detection

Dried M. officinalis seeds were purchased from Attarak online market for herbal medicines, Tehran, Iran. After washing the seeds, $10 \mathrm{~g}$ was added to $100 \mathrm{ml}$ of distilled water and placed in a bath-sonicator at $60{ }^{\circ} \mathrm{C}$ for $30 \mathrm{~min}$.
The extract was then filtered using a Whatman filter (No. 1). The presence of phytochemicals was qualitatively detected as described in the previous study. To detect the flavonoid contents, aluminum nitrate solution $(10 \%$ $\mathrm{W} / \mathrm{V}$ in methanol) and lead acetate $(0.1 \% \mathrm{~W} / \mathrm{V})$ were gently dropped into the $M O$ extract. The appearance of yellow color indicates flavonoids' presence in the sample solution.

\section{Total terpenoids detection}

Total terpenoids were assayed by mixing $2 \mathrm{ml}$ of chloroform with $5 \mathrm{ml}$ of $M O$ extract and $3 \mathrm{ml}$ of sulfuric acid $98 \%$. The formation of a reddish-brown ring interface of the solution indicated the presence of terpenoids.

\section{Total glycosides detection}

Two types of glycosides were examined in the $M O$ extract. First, a ratio of acetic acid: chloroform (1:1 V/V) was mixed with $M O$ extract and vortexed. After that, $1 \mathrm{ml}$ of sulfuric acid $98 \%$ was added and the change of mixture color to green was monitored. The second, a ratio of 10 to $0.5 \mathrm{ml}$ of acetic acid: $\mathrm{FeCl}_{3}(2 \% \mathrm{~W} / \mathrm{V})$ was mixed with $5 \mathrm{ml}$ of $M O$ extract. After a moment, with adding $1 \mathrm{ml}$ of sulfuric acid 98\%, the appearance of a brown ring between the phase layers indicated cardiac steroidal glycosides in the $M O$ extract.

\section{Total phenols and saponin detection}

Total phenolic compounds were detected by adding ferric chloride solution $1 \%$ to the $M O$ extract and the appearance of bluish-black color indicated the presence of phenols. To detect saponins, $5 \mathrm{mg}$ of $M O$ extract was added to $10 \mathrm{ml}$ of distilled water in a $15-\mathrm{ml}$ Falcon tube and vigorously shaken until the formation of a foam layer over the solution.

\section{Biosynthesis of $\mathrm{Ag}_{2} \mathrm{Se}-\mathrm{NCs}$}

To fabricate $\mathrm{Ag}_{2} \mathrm{Se}-\mathrm{NCs}$, the filtrated extract was used as reducing and capping agent. For this purpose, $10 \mathrm{ml}$ of the filtrate was poured into 100 -ml flasks containing $40 \mathrm{ml}$ of deionized water (DW). Then $1 \mathrm{ml}$ of silver nitrate $\left(\mathrm{AgNO}_{3}\right)(1 \mathrm{mM})$ and $0.5 \mathrm{ml}$ of sodium selenite $\left(\mathrm{Na}_{2} \mathrm{SeO}_{3}\right)(0.45 \mathrm{mM})$ solutions were added to the mixture under shaking on a magnetic stirrer for $12 \mathrm{~h}$. The mixture was sonicated with an ultrasonic horn by $50 \mathrm{kHz}$ for $5 \mathrm{~min}$. The gray suspension was centrifuged at $13,000 \mathrm{rpm}$ at $4{ }^{\circ} \mathrm{C}$, washed twice by ethanol $96 \%$ and DW. Finally, the precipitate was dried at $60^{\circ} \mathrm{C}$ in an oven for $24 \mathrm{~h}$.

\section{Characterization of $\mathrm{Ag}_{2} \mathrm{Se}-\mathrm{NCs}$}

After the synthesis of $\mathrm{Ag}_{2} \mathrm{Se}-\mathrm{NCs}$, UV-visible spectroscopy was performed using a spectrophotometer (Jenway 
UV-Vis, 6505 model, UK) at the range of $200-800 \mathrm{~nm}$. FTIR spectrometer (Bruker IFS 66/s, Bruker Optics, Billerica, MA) was applied to study functional groups involved in NPs formation. Transmission electron microscopy (TEM) micrographs were taken with a TEM instrument (Philips EM 208S, Netherlands). Morphological and elemental properties were studied through SEM and energy dispersive X-ray (EDX) analyses using FESEM TESCAN MIRA3. X-ray diffraction (XRD) of biosynthesized $\mathrm{Ag}_{2} \mathrm{Se}-\mathrm{NCs}$ was carried out using an XRD diffractometer (Rigaku Ultima IV) in the normal angle range $\left(10-80{ }^{\circ} \mathrm{C}\right)$. The dynamic Light Scattering (DLS) and zeta potential (ZP) of $\mathrm{Ag}_{2} \mathrm{Se}-\mathrm{NCs}$ were determined by a DLS instrument (VASCO, CORDOUAN TECHNOLOGIES, England).

\section{Preparation of $\mathrm{Ag}_{2} \mathrm{Se}-\mathrm{NCs}$ for bioassay experiments}

The dry powder of $\mathrm{Ag}_{2} \mathrm{Se}-\mathrm{NCs}$ was weighed and then dispersed in distilled water in the desired amounts. The $\mathrm{Ag}_{2} \mathrm{Se}-\mathrm{NCs}$ mixture was placed in a bath-sonicator for 1 $\mathrm{h}$ to achieve high homogeneity and reduce aggregation. After that, the suspension was then passed through a $0.45-\mu \mathrm{m}$ filter paper and the filtrate was applied for biological assays.

\section{Antimicrobial assay of $\mathrm{Ag}_{2} \mathrm{Se}-\mathrm{NCs}$}

The antimicrobial activity of biosynthesized $\mathrm{Ag}_{2} \mathrm{Se}-\mathrm{NCs}$ was carried out by the agar well-diffusion method against $\beta \mathrm{L}$-resistant $P$. aeruginosa. Imipenem $(10 \mu \mathrm{g} / \mathrm{ml})$ was used as a positive control for bacteria. Bacterial cells were spread on the agar plates using sterile swab; then, $20 \mu \mathrm{l}$ of different concentrations of $\mathrm{Ag}_{2} \mathrm{Se}-\mathrm{NCs}(1.5-100 \mu \mathrm{g} / \mathrm{ml})$ were added to each well. After $24 \mathrm{~h}$ incubation at $37^{\circ} \mathrm{C}$, the growth inhibition zone was measured using a ruler.

Minimum inhibitory concentration (MIC) was determined using the micro-dilution method in 96-well plates. Fifty microliter of $\mathrm{Ag}_{2} \mathrm{Se}-\mathrm{NCs}$ dilutions $(0-100 \mu \mathrm{g} / \mathrm{ml})$ were added to $50 \mu \mathrm{l}$ of Muller-Hinton broth (MHB) containing $10^{6} \mathrm{CFU} / \mathrm{ml}$ of bacterial cells. After $24 \mathrm{~h}$, the MIC value of $\mathrm{Ag}_{2} \mathrm{Se}-\mathrm{NCs}$ was determined in terms of triphenyl tetrazolium chloride (TTC) reduction rate. Minimum bactericidal concentration (MIC) was obtained from MIC value as described previously (Sibiya and Moloto 2016).

\section{Antibiofilm activity}

Biofilm formation of $P$. aeruginosa was studied in the presence of $\mathrm{Ag}_{2} \mathrm{Se}-\mathrm{NCs}$ sub-MIC in a 96-well plate. Briefly, $10^{6} \mathrm{CFU} / \mathrm{ml}$ of bacterial cells were added to 200 $\mu \mathrm{L}$ of LB broth medium supplemented with 1.56 and $3.12 \mu \mathrm{g} / \mathrm{ml}$ of NPs. After $24 \mathrm{~h}$ incubation, non-adherent bacterial cells were removed. The adhered biofilms were stained with $0.1 \%$ crystalline violet solution for $5 \mathrm{~min}$.
Excess colors was then removed using DW and the biofilm was destained with $200 \mu \mathrm{l}$ glacial acetic acid $35 \%$. After that, the plate was slowly agitated for $2 \mathrm{~min}$ and the absorbance was determined by a microplate reader at $570 \mathrm{~nm}$. The following equation (Eq. 1) was used to determine the antibiofilm efficacy of $\mathrm{Ag}_{2} \mathrm{Se}-\mathrm{NCs}$ :

$$
\begin{aligned}
& \text { Antibiofilm efficacy }(\%) \\
& =\frac{\text { Control(OD) }- \text { treated }(\mathrm{OD})}{\operatorname{control}(\mathrm{OD})} \times 100 .
\end{aligned}
$$

The adhesion ability of the bacterial biofilm was visualized by a qualitative method. Briefly, the bacterial cells were cultured in broth media supplemented with certain concentrations of $\mathrm{Ag}_{2} \mathrm{Se}-\mathrm{NCs}$, ( 25 and $50 \%$ of MIC) in contact with glass slides. After that, the bacterial biofilms were stained with $200 \mu \mathrm{l}$ of crystal violet $(1 \% \mathrm{w} / \mathrm{v})$. The slides were then rinsed with $70 \%$ ethanol, washed by DW and dried at room temperature. Finally, the biofilms were photographed under a light microscope. Further, 3D topographical studies of treated and untreated biofilms were studied using atomic force microscopy (AFM).

\section{Antioxidant assays}

The antioxidant capacities of $\mathrm{Ag}_{2} \mathrm{Se}-\mathrm{NCs}$ and $\mathrm{MO}$ extract were examined using DPPH radical scavenging method. Briefly, different concentrations $(10-1000 \mu \mathrm{g} /$ $\mathrm{ml}$ ) of $\mathrm{Ag}_{2} \mathrm{Se}-\mathrm{NCs}$ and $\mathrm{MO}$ extract were added to methanol solution of DPPH reagent $(0.1 \mathrm{mM})$ and remained for $30 \mathrm{~min}$ in darkness. The ascorbic acid was used as a positive control and ethanol as a blank in this assay. The scavenging percentage of DPPH was calculated by the following equation:

$$
\text { Scavenging efficacy }(\%)=\frac{\operatorname{Blank}(\mathrm{A} 0)-\text { Sample }(\mathrm{A})}{\operatorname{Blank}(\mathrm{A} 0)} \times 100 .
$$

\section{Cytotoxicity assay}

Cellular toxicity of $\mathrm{Ag}_{2} \mathrm{Se}-\mathrm{NCs}$ and $\mathrm{MO}$ extract against HepG2 cell line was studied using the MTT assay method. For this, the cells $\left(1 \times 10^{4}\right.$ cells/well $)$ were grown in a 96-well plate containing RPMI supplemented with $10 \% \mathrm{FBS}$, penicillin (100 IU/l) and streptomycin (100 mg/l) and incubated at $37{ }^{\circ} \mathrm{C}$ under $5 \% \mathrm{CO}_{2}$ and $95 \%$ humidity conditions. After reaching about $75 \%$ confluence, the medium was refreshed with a medium containing serially diluted $\mathrm{Ag}_{2} \mathrm{Se}-\mathrm{NCs}$ and the cells were again incubated for $24 \mathrm{~h}$. After that, to each well, $100 \mu \mathrm{l}$ of the MTT [3-(4, 5-dimethylthiozol-2-yl)-3,5-diphenyl tetrazolium bromide] (Sigma) solution was added and incubated at $37{ }^{\circ} \mathrm{C}$ for $4 \mathrm{~h}$. Further, the medium containing unreduced MTT reagent was gently removed and the wells 

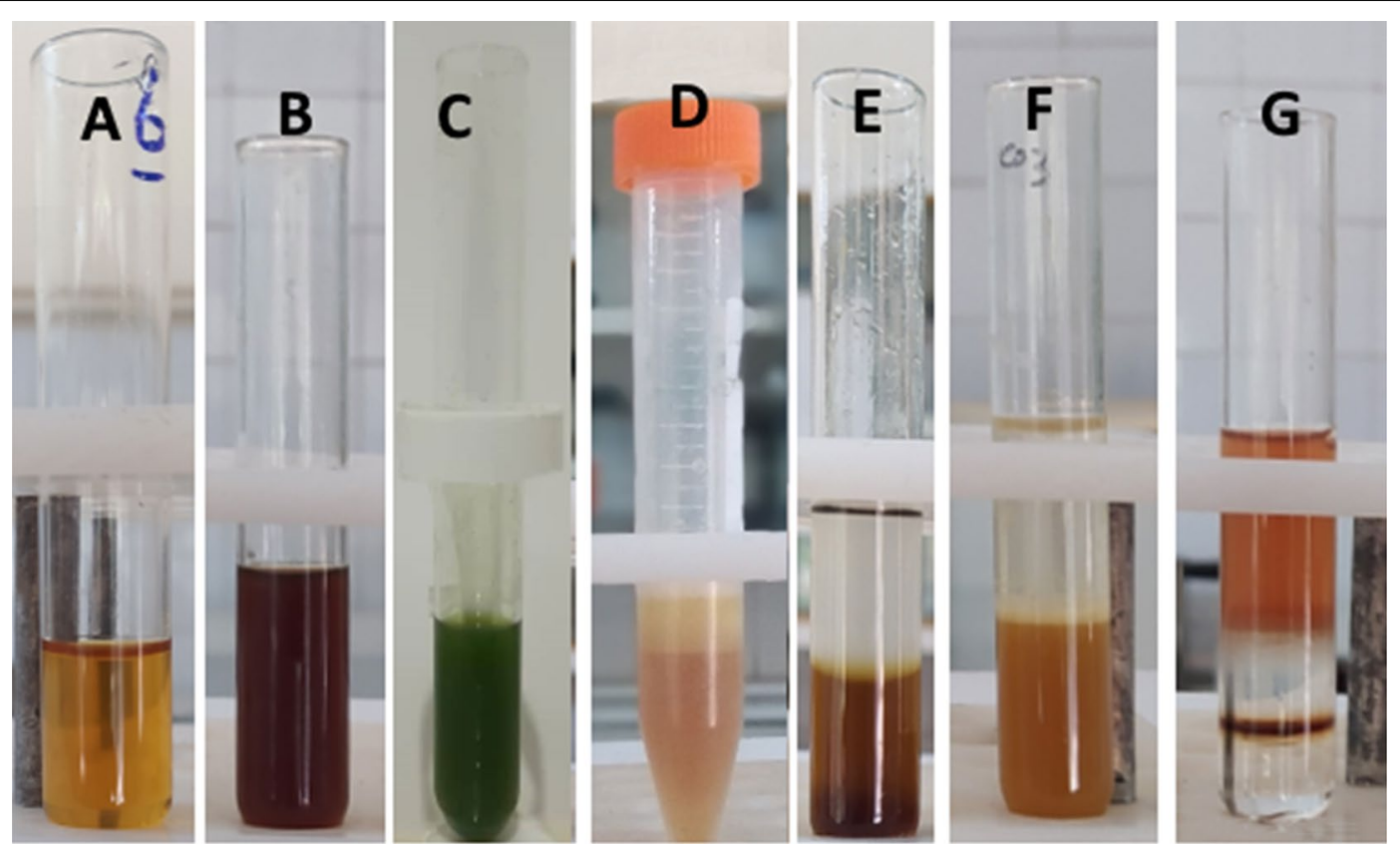

Fig. 1 Qualitative assay of phytochemical contents in MO extract. a Flavonoids, $\mathbf{b}$ terpenoids, $\mathbf{c}$ aglycone steroidal glycoside, $\mathbf{d}$ saponin, e polyphenols, $\mathbf{g}$ cardiac steroidal glycosides

were treated with $200 \mu \mathrm{l}$ of dimethyl sulfoxide (DMSO). To solubilize the formazan crystals, the plate was shaken for $15 \mathrm{~min}$ and then the absorbance solution was measured at $595 \mathrm{~nm}$ using an ELISA microplate reader. The viability of the cells was calculated by Eq. 2 as follows:

$$
\text { Viability }(\%)=\frac{\text { Absorbance of treated sample(A) }}{\text { Absorbance of control(A0) }} \times 100 .
$$

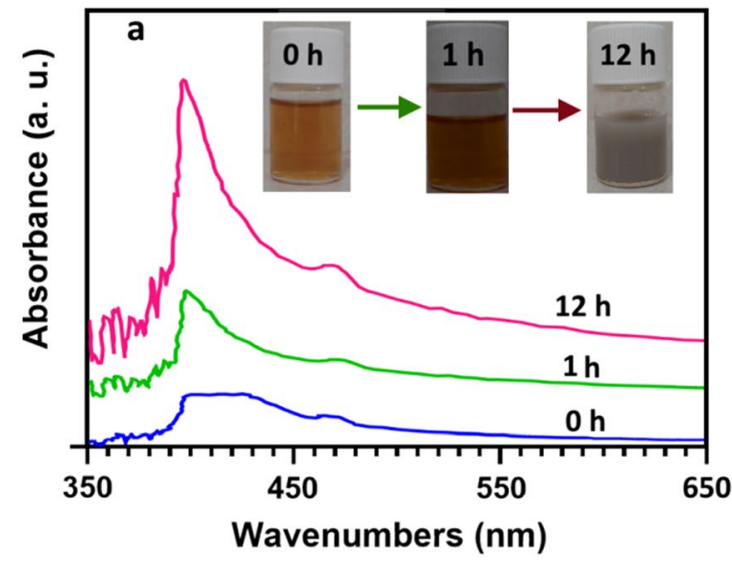

Fig. 2 a UV-visible absorption and $\mathbf{b}$ FTIR spectra of $\mathrm{Ag}_{2} \mathrm{Se}-\mathrm{NCS}$

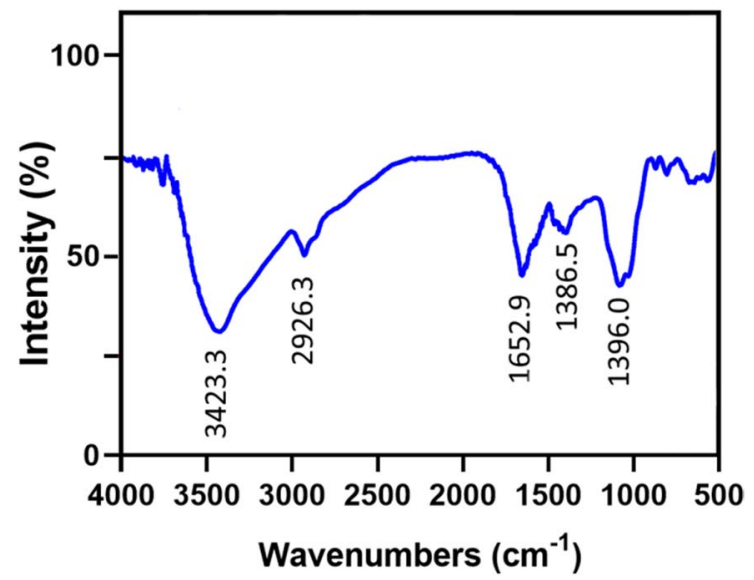



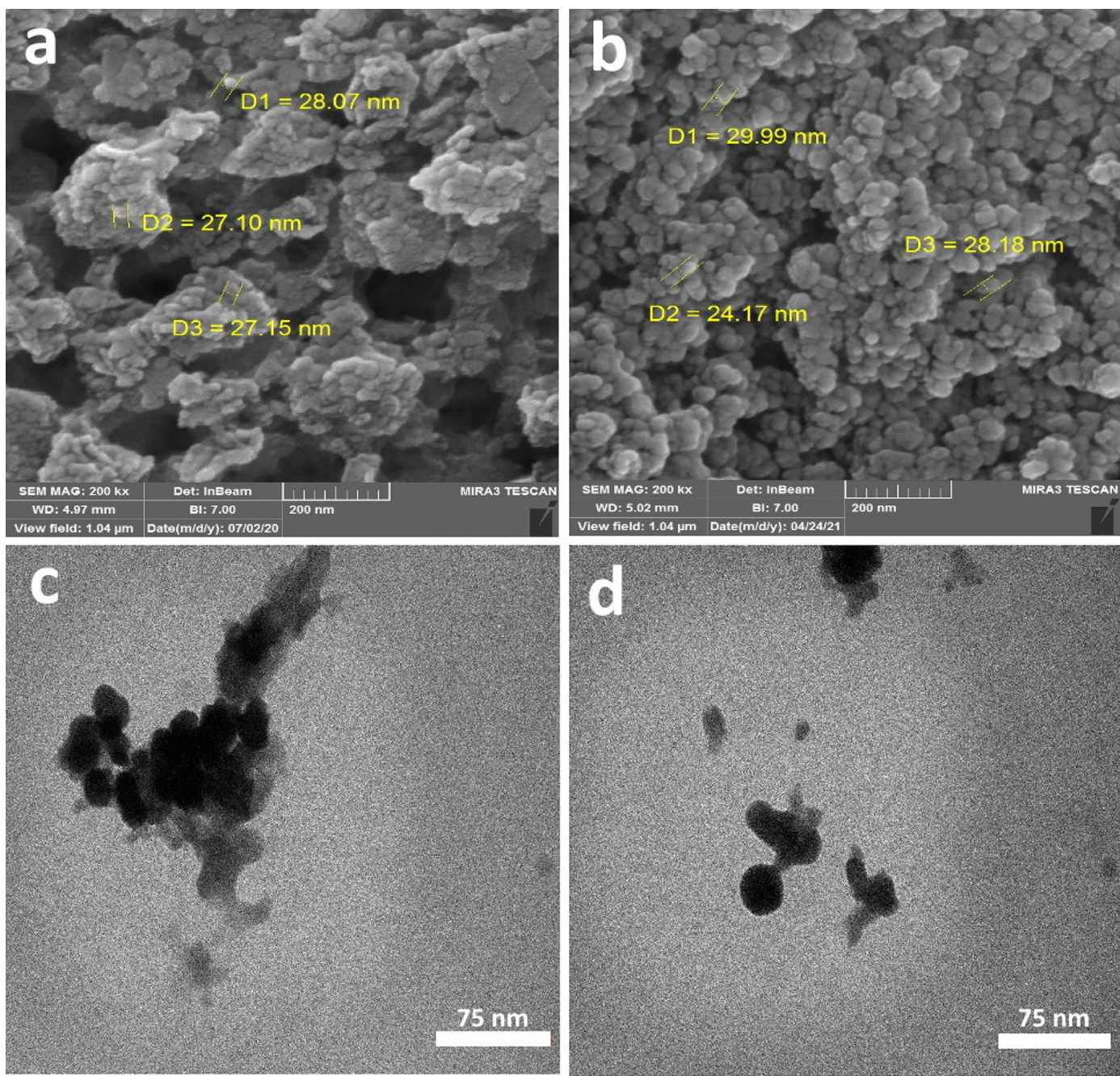

Fig. 3 a, b SEM, c, d TEM images of biosynthesized $\mathrm{Ag}_{2} \mathrm{Se}-\mathrm{NCS}$

\section{Results and discussion}

\section{Phytochemical analysis of $\mathrm{MO}$ extract}

Phytochemical compounds in $M O$ extract were quantitatively identified using standard methods based on colorimetric observations. As shown in Fig. 1, terpenoids, flavonoids, glycosides, polyphenols, and saponins were detected in $M O$ extract. Many studies have previously demonstrated that $M$. officinalis contains major biologically active metabolites such as flavonoids, coumarins, steroid glycosides, saponins and other compounds (Liu et al 2018). Additionally, biological compounds responsible for biosynthesizing the most NPs include phenolic compounds, flavonoids, fatty acids, reducing sugars and polyhydric alcohols (Kanchi et al. 2020; Loeschner et al. 2011; Tripathy et al. 2020; Vorobyev et al. 2018). Therefore, the high potential of $M O$ extract for the synthesis of various metal NPs can be attributed to these active metabolites.

\section{$\mathrm{Ag}_{2} \mathrm{Se}-\mathrm{NCs}$ synthesis and characterization}

The aqueous extract of $M$. officinalis was used for the synthesis of $\mathrm{Ag}_{2} \mathrm{Se}-\mathrm{NCs}$ from $\mathrm{AgNO}_{3}$ and $\mathrm{Na}_{2} \mathrm{SeO}_{3}$ as silver and selenium sources, respectively. After stirring for $6 \mathrm{~h}$, the reaction mixture's color changed from orange to gray, as seen in Fig. 2a. This discoloration is possibly due to the excitation of the silver ion surface's plasmon resonance in the $\mathrm{Ag}_{2} \mathrm{Se}-\mathrm{NCs}$ (García et al. 2020). The existence of $\mathrm{Ag}_{2} \mathrm{Se}-\mathrm{NCs}$ was also established by the appearance of an absorption band between 350 and $450 \mathrm{~nm}$ with an absorption intensity at $395.61 \mathrm{~nm}$ compared with other studies (Fig. 2a) (Delgado-Beleño et al. 2018; García et al 2020; Martinez-Nuñez et al. 2017). In the formation of $\mathrm{Ag}_{2} \mathrm{Se}-\mathrm{NCs}$, first selenium ions are reduced to $\mathrm{Se}_{2}$ and then co-precipitation occurs with Ag cations. Thus, with 

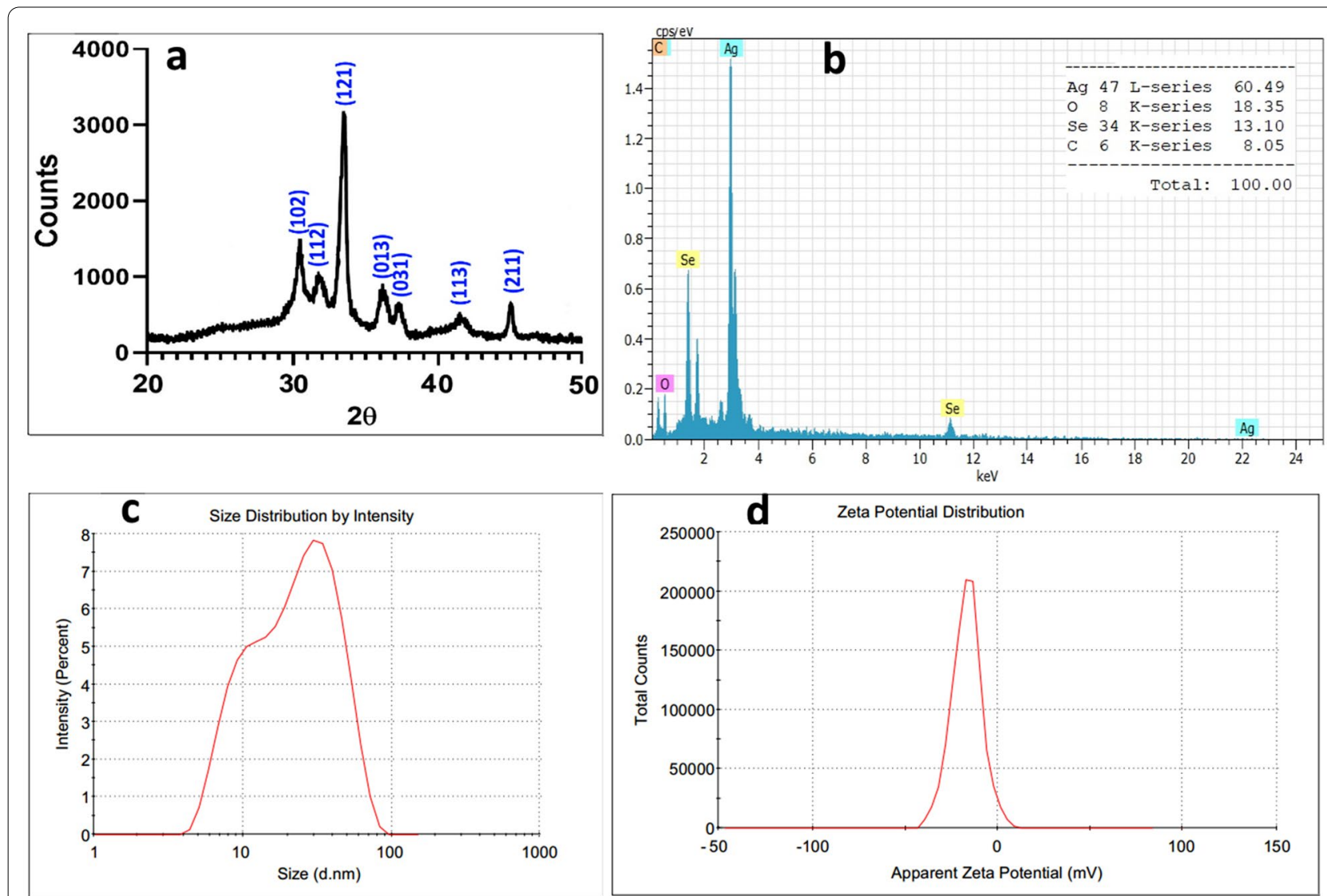

Fig. 4 a XRD pattern, b EDS profile, c particle size distribution (DLS) and $\mathbf{d}$ zeta potential (surface charge) of biosynthesized $\mathrm{Ag}_{2} \mathrm{Se}_{\mathrm{N}} \mathrm{NCS}$

lasting reaction time and the reducing selenium by the biomolecules, the adsorption spectrum reaches a steadystate, indicating the presence of a biomolecular matrix as a stabilizer of $\mathrm{Ag}_{2} \mathrm{Se}-\mathrm{NCs}$ (Sidorova et al. 2018).

FTIR analysis was conducted to determine the functional interactions between biomolecules and $\mathrm{Ag}_{2} \mathrm{Se}-\mathrm{NCs}$ (Fig. 2b). The spectrum of biosynthesized $\mathrm{Ag}_{2} \mathrm{Se}-\mathrm{NCs}$ showed an $\mathrm{O}-\mathrm{H}$ stretch at $3423.3 \mathrm{~cm}^{-1}$ corresponding to hydroxyl groups of biological compounds involved in NPs synthesis (Sytu and Camacho 2018). Notable transmission peaks appeared at 1652.9 and $1396 \mathrm{~cm}^{-1}$, indicating the presence of $\mathrm{Ag}-\mathrm{Se}$ bond in the NPs structure (Chougale et al. 2013; Kalishwaralal et al. 2016).

The SEM image shows that the grain of NPs is spherical in shape, about $30 \mathrm{~nm}$, with agglomeration at some places (Fig. 3a, b). Additionally, the TEM image confirmed that the synthesized $\mathrm{Ag}_{2} \mathrm{Se}-\mathrm{NCs}$ were spherical with the particle size from 30-40 nm, which agrees with the SEM analysis (Fig. 3c, d).

As shown in Fig. 4a, the powder XRD patterns represent the formation of $\beta-\mathrm{Ag}_{2} \mathrm{Se}$ with an orthorhombic crystal structure according to the literature (Ayele 2016; Gholami et al 2018; Sibiya and Moloto 2017). Further, the EDX pattern confirmed the elemental abundance of silver, selenium, oxygen and carbon in the $\mathrm{Ag}_{2} \mathrm{Se}$ nanostructure (Fig. $4 \mathrm{~b}$ ). The size of $\mathrm{Ag}_{2} \mathrm{Se}$ crystals was calculated according to the Scherer equation to be about $38.3 \mathrm{~nm}$, close to SEM and TEM estimations. Additionally, the size distribution curve (DLS) measured a hydrodynamic diameter range of 5-100 $\mathrm{nm}$ with a maximum intensity of $51.7 \mathrm{~nm}$ in a liquid phase (Fig. 4c).

As seen in Fig. 4d, the zeta potential of $\mathrm{Ag}_{2} \mathrm{Se}-\mathrm{NCs}$ in PBS was calculated to be $-15.5-\mathrm{mv}$. As reported in the literature, NPs with a surface charge of between -30 and $+30 \mathrm{mV}$ have higher electrostatic stability. On the other hand, bioactive metabolites' role in the stability of NPs was well-established. Therefore, capping agents' existence is crucial to avoid the aggregation of NPs under physiological conditions (Loeschner et al 2011; Vorobyev et al 2018).

\section{Antibacterial activity studies}

Antibacterial activity of $\mathrm{Ag}_{2} \mathrm{Se}-\mathrm{NCs}$ was measured against $P$. aeruginosa using WDM, MIC and MBC methods. The results showed potent growth inhibition at 


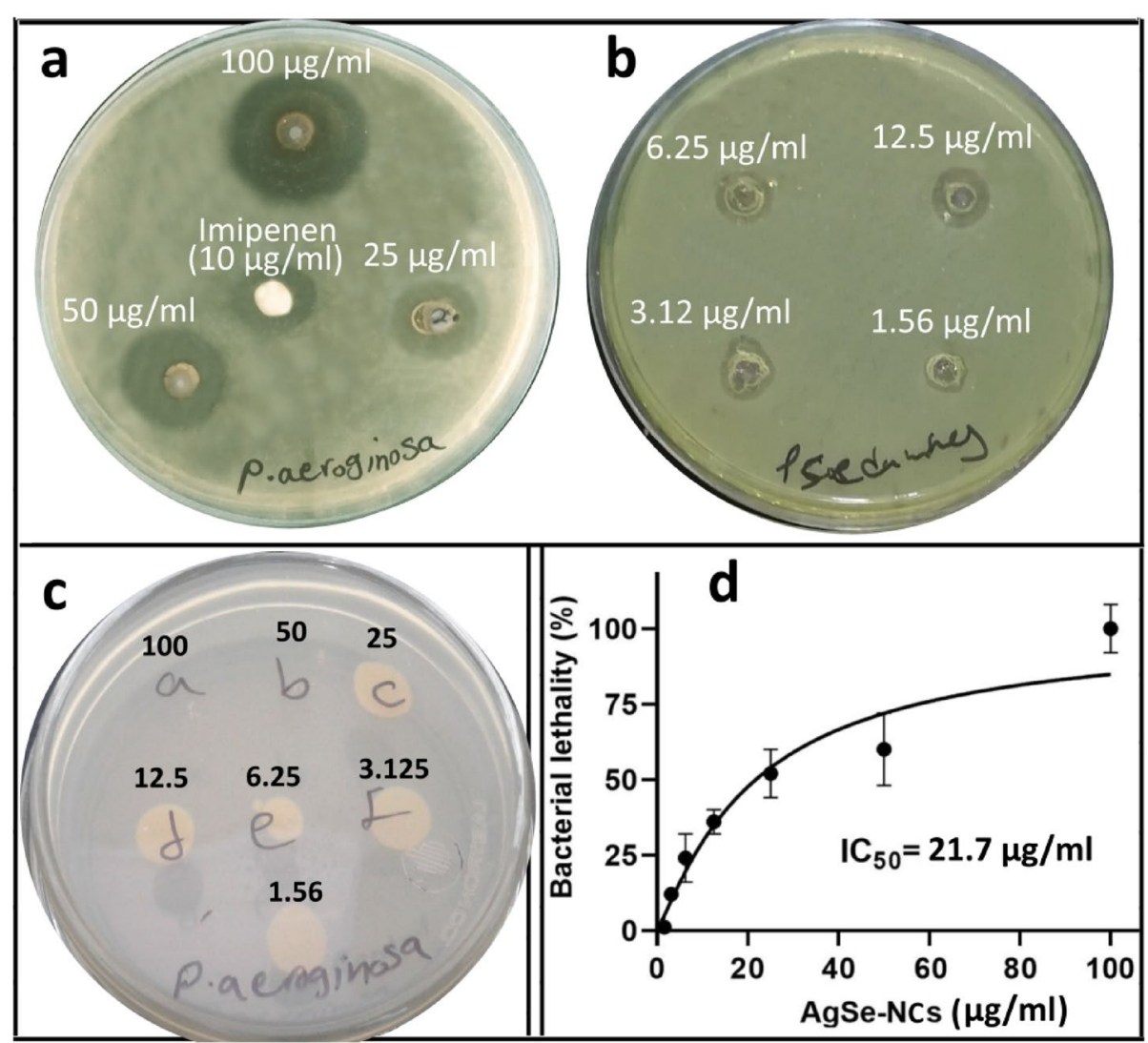

Fig. 5 Antimicrobial studies of $\mathrm{Ag}_{2} \mathrm{Se}-\mathrm{NCS}$ against P. aeruginosa (ATCC 27853) at different concentrations (1.56-100 $\mu \mathrm{g} / \mathrm{ml}$ ). a, b Agar well-diffusion assay, $\mathbf{c}$ MBC on the agar plate and $\mathbf{d} I \mathrm{C}_{50}$ value in terms of MIC results

$100 \mu \mathrm{g} / \mathrm{ml}$ with a MIC and MBC values of 6.25 and $50 \mu \mathrm{g} /$ $\mathrm{ml}$, respectively (Fig. $5 \mathrm{a}-\mathrm{c}$ ). In this regard, Garcia et al. (2020) have shown that sugar-coated $\mathrm{Ag}_{2} \mathrm{Se}-\mathrm{NPs}$ have a robust inhibitory effect on various pathogens, especially Gram-positive bacteria. Contrary to our findings, they reported a greater antimicrobial activity against Grampositive bacteria (García et al 2020). In the green synthesis of metallic NPs, reducing and capping agents are critical factors for their biological properties so that bioactive compounds can modulate the biological functions of biosynthesized NPs. Various bioactive metabolites include glycosides, saponins, polyphenols, flavonoids, coumarins and alkaloid derivatives with antioxidant, antimicrobial, anticancer, antibiofilm and anti-inflammatory properties, have been reported (Liu et al 2018; Mladenović et al. 2016). However, few studies have been performed on the biosynthesis of NPs by $M$. officinalis metabolites. In one study, Sidorova et al. (2018) reported the antibiotic and antimicrobial effects of silver NPs synthesized with aqueous $M O$ extract against $E$. coli and $P$. aeruginosa (Sidorova et al 2018).

\section{Antibiofilm studies}

Antibiofilm activity assay was performed based on the adhesion ability of $P$. aeruginosa on the glass slide in the presence of different concentrations of $\mathrm{Ag}_{2} \mathrm{Se}-\mathrm{NCs}$. According to the AFM histogram in Fig. 6a, b, the area and height of the biofilm formed by $P$. aeruginosa in the treated and untreated samples are significantly different. The 3D topographic image also confirms the reduction in the level and height of the biofilm (Fig. 6a, b). Furthermore, Fig. $6 \mathrm{c}-\mathrm{e}$ represents the light microscopic images of biofilm formation by $P$. aeruginosa in the presence of 3.125 and $1.56 \mu \mathrm{g} / \mathrm{ml}$ of $\mathrm{Ag}_{2} \mathrm{Se}-\mathrm{NCs}$. With a qualitative evaluation, biofilm inhibition of $\mathrm{Ag}_{2} \mathrm{Se}-\mathrm{NCs}$ is a dose-dependent process, so that with increasing the $\mathrm{Ag}_{2} \mathrm{Se}-\mathrm{NCs}$ concentration, the density of the bacterial biofilm was significantly decreased. Many reports have shown that NPs can penetrate bacterial cells and increase its permeability (Subhanandaraj et al. 2020). Metallic NPs bind to biomolecules such as thiol and phosphate groups, disrupting enzyme function and genome integrity (Jiang et al. 2018; Shaikh et al. 2019). The antibiofilm activity of 


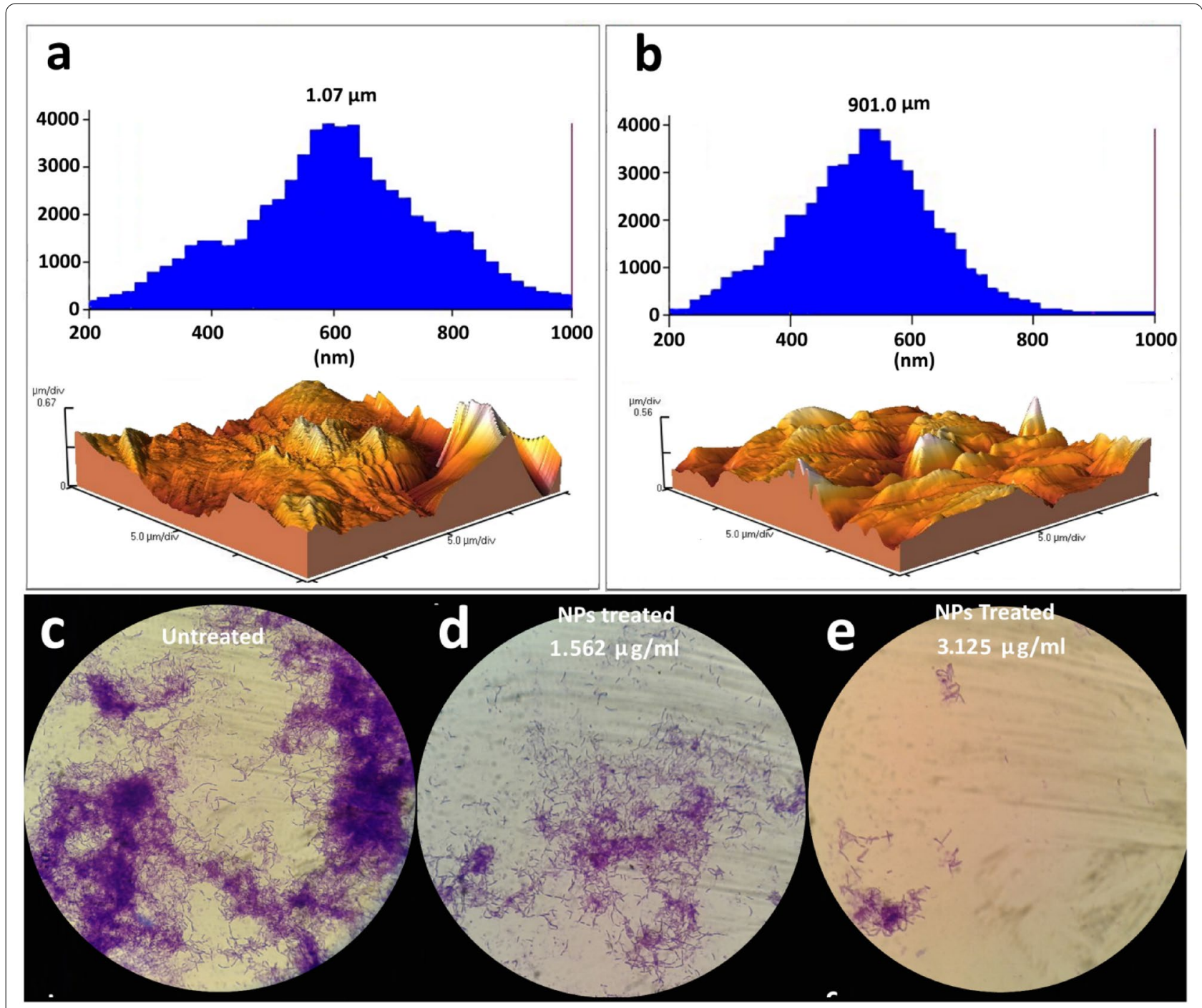

Fig. 6 Atomic force microscopy of $P$. aeruginosa biofilm $\mathbf{a}$ untreated and $\mathbf{b}$ treated with $\mathrm{Ag}_{2} \mathrm{Se}-\mathrm{NCs}$. Comparative light microscopic images of $P$. aeruginosa biofilm among c untreated, $\mathbf{d}$ treated with $1.56 \mu \mathrm{g} / \mathrm{ml}$ of $\mathrm{Ag}_{2} \mathrm{Se}-\mathrm{NCs}$ and $\mathbf{e}$ treated with $3.125 \mu \mathrm{g} / \mathrm{ml}$ of $\mathrm{Ag}_{2} \mathrm{Se}-\mathrm{NCs}$

NPs can be due to the inhibition of enzymes involved in the biofilm formation (Gabal et al. 2019; Shah et al. 2019). Qayyum and Khan (2016) suggest that the destruction of the biofilm structure by nanoparticles can sensitize resistant bacteria to antibiotics (Qayyum and Khan 2016).

\section{Antioxidant activity assessment}

The antioxidant capacity of $\mathrm{Ag}_{2} \mathrm{Se}-\mathrm{NCs}, \mathrm{MO}$ extract and ascorbic acid, were calculated according to $\mathrm{IC}_{50}$, as shown in Fig. $7 \mathrm{a}-\mathrm{c}$, respectively. Accordingly, the $\mathrm{IC}_{50}$ values calculated for the antioxidant capacity of $\mathrm{Ag}_{2} \mathrm{Se}-\mathrm{NCs}$ and $\mathrm{MO}$ extract were 58.5 and $220.13 \mu \mathrm{g} / \mathrm{ml}$, respectively. According to the literature, the antioxidant activity of NPs is probably due to their ability to donate electrons and inhibit free radicals' formation. $\mathrm{Ag}_{2} \mathrm{Se}-\mathrm{NCs}$ showed that it has a high potential in scavenging DPPH as a standard model of free radical. Studies show that natural antioxidants can reduce the risk of chronic diseases such as cancer by eliminating free radicals (Kanipandian and Thirumurugan 2014).

On the other hand, studies show that flavonoids and phenolic acids in $M$. officinalis have strong antioxidant capacity. Therefore, potent bioactive compounds can enhance the medicinal properties of biosynthesized NPs (Dobrucka 2020; Liu et al 2018). Since bioactive 

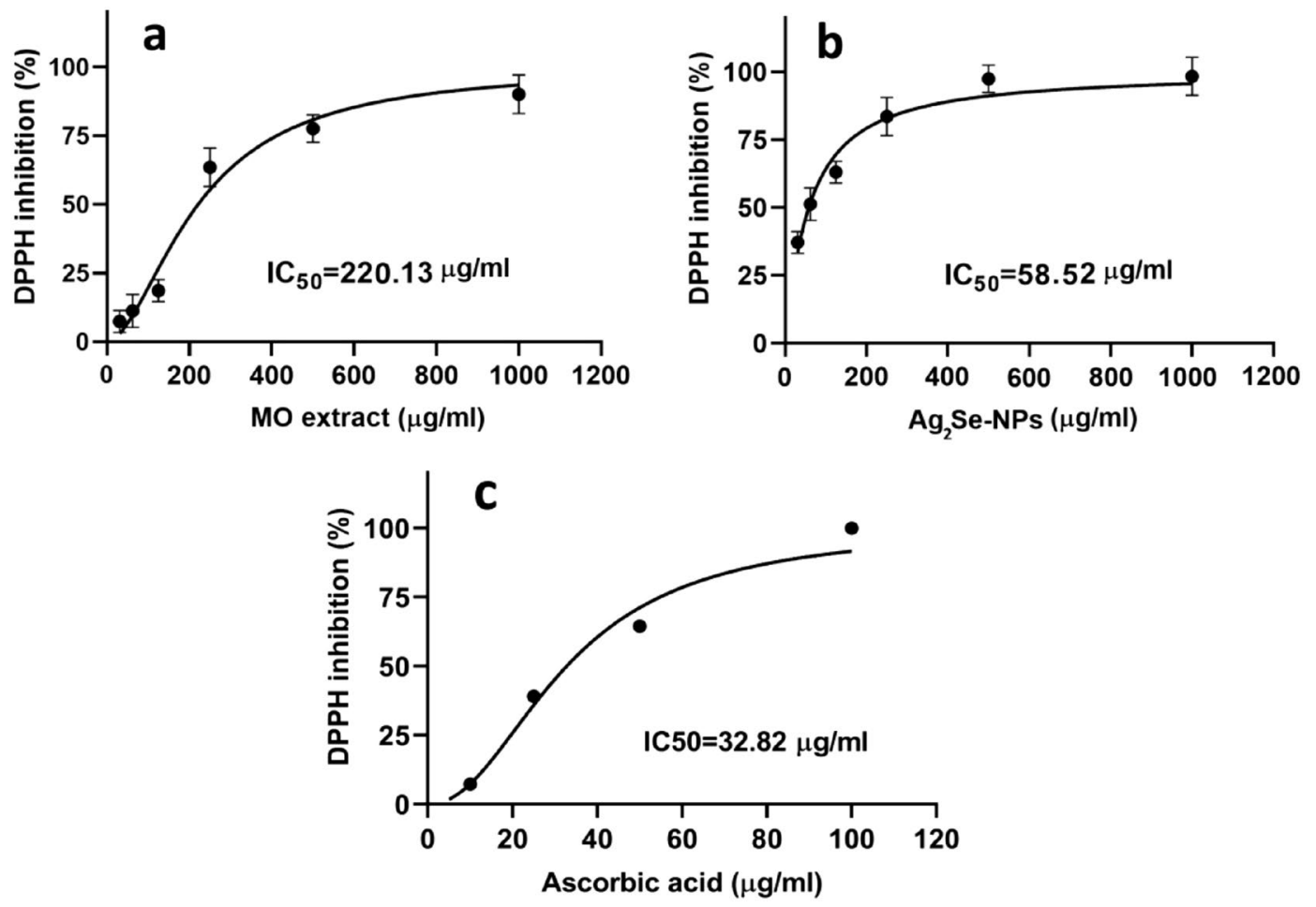

Fig. 7 Antioxidant activities of $\mathbf{a} \mathrm{Ag}_{2} \mathrm{Se}-\mathrm{NCs}, \mathbf{b} \mathrm{MO}$ extract and $\mathbf{c}$ ascorbic acid (control)

metabolites in M. officinalis extract was confirmed to be strong biological activities and act as capping agents in NPs synthesis, they can exert a synergistic effect on the bioactivity of $\mathrm{Ag}_{2} \mathrm{Se}$-NCs (Abdelghany et al. 2020; Sytu and Camacho 2018).

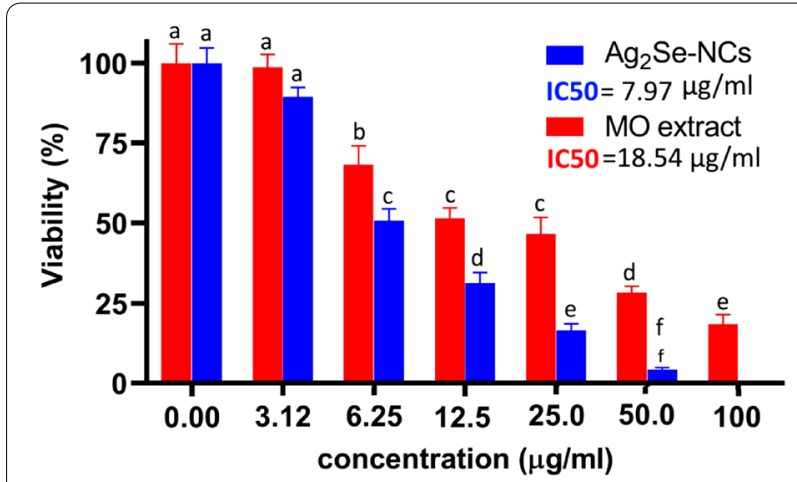

Fig. 8 Cytotoxicity of $\mathrm{Ag}_{2} \mathrm{Se}-\mathrm{NCS}$ and MO extract in HepG2 cell line. Data are presented as mean \pm SD with significant differences of $p<0.001$. Different superscript shows significant differences between groups

\section{Cytotoxicity effects of $\mathrm{Ag}_{2} \mathrm{Se}-\mathrm{NCs}$}

The effect of cytotoxicity of $\mathrm{Ag}_{2} \mathrm{Se}-\mathrm{NCs}$ on $\mathrm{HepG} 2$ cell line was dose-dependent so that with increasing its concentration, cell survival was significantly reduced. As shown in Fig. 8, the cytotoxicity of $\mathrm{Ag}_{2} \mathrm{Se}-\mathrm{NCs}$ was higher than $M O$ extract, so that the $\mathrm{IC}_{50}$ values of $\mathrm{Ag}_{2} \mathrm{Se}-\mathrm{NCs}$ and $M O$ extract were 7.97 and $17.44 \mu \mathrm{g} / \mathrm{ml}$, respectively. Studies have demonstrated that a wide range of mechanisms such as metabolic and structural interactions are involved in the cytotoxicity of NPs (Hemanth Kumar et al. 2019; Reyes-Torres et al. 2019). Kanipandian et al. (2014) evaluated the mechanism of action of cytotoxicity of silver NPs. They concluded that NPs stimulate apoptosis by disrupting cell membrane integrity, inhibiting metabolic pathways, and generating free radicals in the cells (Kanipandian et al. 2014). In this respect, biosynthesized NPs demonstrate more compatibility than chemically synthesized ones so that normal cells do not undergo significant disturbances (Marslin et al. 2018). In the present study, although $\mathrm{Ag}_{2} \mathrm{Se}-\mathrm{NCs}$ have more toxicity than the $M O$ extract, due to its promising antioxidant properties, it may modulate its toxic effects and increase its biocompatibility (Alves et al. 2019). 


\section{Conclusion}

$\mathrm{Ag}_{2} \mathrm{Se}-\mathrm{NCs}$ were first successfully synthesized as a reducing and capping agent with $M$. officinalis extract. The results showed that biosynthesized $\mathrm{Ag}_{2} \mathrm{Se}-\mathrm{NCs}$ show promising antimicrobial, antibiotic, antioxidant and cytotoxic activities. It really should be mentioned that almost no attention has been paid in earlier studies to the biological properties of $\mathrm{Ag}_{2} \mathrm{Se}-\mathrm{NCs}$. In this study, the growth inhibitory and antibiofilm activities of $\mathrm{Ag}_{2} \mathrm{Se}-\mathrm{NCs}$ against antibiotic-resistant $P$. aeruginosa (ATCC 27853) were found to have satisfactory efficacy. Therefore, owing to the advent of new resistant bacteria, our findings could pave the way for the use of $\mathrm{Ag}_{2} \mathrm{Se}-\mathrm{NCs}$ as an antimicrobial agent. Taken together, although the biological function of $\mathrm{Ag}_{2} \mathrm{Se}-\mathrm{NCs}$ seems to be satisfactory, more in-depth studies are required to recognize the molecular mechanisms and their possible side effects.

\section{Abbreviations \\ $\mathrm{Ag}_{2} \mathrm{Se}-\mathrm{NCs}$ : Silver selenide nano-chalcogens; FTIR: Fourier transform infrared spectroscopy; UV-VIS: Ultraviolet-visible; NP: Nanoparticle; MNP: Metallic nanoparticle; W/V: Weight/volume; SEM: Scanning electron microscopy; EDX: Energy dispersive X-ray; DLS: Dynamic light scattering; MO: Melilotus officinalis; ZP: Zeta potential.}

\section{Acknowledgements}

The authors would like to express their gratitude to Lorestan University of Medical Sciences'Vice Chancellor for Research and Technology for providing research facilities for this study. It is worth remembering that this research was carried out at the Razi Herbal Medicines Research Center.

\section{Authors' contributions \\ SZM and HEL performed the experiments, nanoparticle synthesis and micro- biological assays. MK analyzed the data and prepared figures and tables. KS prepared plant extract and performed cytotoxicity assays. AKA contributed in draft preparation and editing. AM designed and supervised all experiments, prepared the manuscript draft, processed the primary data and interpreted all results. All authors thoroughly acknowledged the final draft of the manuscript. All authors read and approved the final manuscript.}

\section{Funding}

The work was financially supported by Lorestan University of Medical Sciences.

\section{Availability of data and materials}

All data obtained in this study are fully analyzed and presented in the manuscript.

\section{Declarations}

Ethics approval and consent to participate

All authors are fully aware of the publication ethics and have agreed to publish the manuscript.

\section{Consent for publication}

All authors agreed to the manuscript being published in the Journal of Bioresources and Bioprocessing.

\section{Competing interest}

There are no conceivable conflicts of interest which need to be declared.

\section{Author details}

${ }^{1}$ Razi Herbal Medicines Research Center, Lorestan University of Medical Sciences, P.O. Box: 6816889468, Khorramabad, Iran. ${ }^{2}$ Biotechnology Department, Faculty of Medicine, Lorestan University of Medical Sciences, Khorramabad, Iran. ${ }^{3}$ Isfahan Gastroenterology and Hepatology Research Center (IGHRC), Isfahan University of Medical Sciences, Isfahan, Iran. ${ }^{4}$ Iraqi Ministry of Education, Baghdad, Iraq.

Received: 2 March 2021 Accepted: 28 June 2021

Published online: 02 July 2021

\section{References}

Abdelghany AM, Ayaad DM, Mahmoud SM (2020) Antibacterial and energy gap correlation of PVA/SA biofilms doped with selenium nanoparticles. Biointerface Res Appl Chem 10(5):6236-6244. https://doi.org/10.33263/ BRIAC105.62366244

Alves MM, Andrade SM, Grenho L, Fernandes MH, Santos C, Montemor MF (2019) Influence of apple phytochemicals in ZnO nanoparticles formation, photoluminescence and biocompatibility for biomedical applications. Mater Sci Eng C 101:76-87. https://doi.org/10.1016/j.msec.2019. 03.084

Anthony SP (2009) Synthesis of $\mathrm{Ag}_{2} \mathrm{~S}$ and Ag2Se nanoparticles in self assembled block copolymer micelles and nano-arrays fabrication. Mater Lett 63(9-10):773-776. https://doi.org/10.1016/j.matlet.2008.12.051

Ayele DW (2016) A facile one-pot synthesis and characterization of Ag2Se nanoparticles at low temperature. Egypt J f Basic Appl Sci 3(2):149-154. https://doi.org/10.1016/j.ejbas.2016.01.002

Chougale U, Han S-H, Rath M, Fulari V (2013) Synthesis, characterization and surface deformation study of nanocrystalline $\mathrm{Ag}_{2} \mathrm{Se}$ thin films. Mater Phys Mech 17(1):47-58

Delgado-Beleño Y, Martinez-Nuñez C, Cortez-Valadez M, Flores-López N, Flores-Acosta M (2018) Optical properties of silver, silver sulfide and silver selenide nanoparticles and antibacterial applications. Mater Res Bull 99:385-392

Dobrucka R (2020) Biogenic synthesis of trimetallic nanoparticles Au/ZnO/Ag using Meliloti officinalis extract. Int J Environ Anal Chem 100(9):981-991. https://doi.org/10.1080/03067319.2019.1646736

Gabal RA, Shalaby RM, Abdelghany A, Kamal M (2019) Antimicrobial effect, electronic and structural correlation of nano-filled tin bismuth metal alloys for biomedical applications. Biointerface Res Appl Chem 9(5):43404344. https://doi.org/10.33263/BRIAC95.340344

García DA, Mendoza L, Vizuete K, Debut A, Arias MT, Gavilanes A et al (2020) Sugar-mediated green synthesis of silver selenide semiconductor nanocrystals under ultrasound irradiation. Molecules 25(21):5193. https:// doi.org/10.3390/molecules25215193

Gholami M, Shahzamani K, Marzban A, Lashgarian HE (2018) Evaluation of antimicrobial activity of synthesised silver nanoparticles using Thymus kotschyanus aqueous extract. IET Nanobiotechnol 12(8):1114-1117. https://doi.org/10.1049/iet-nbt.2018.5110

Gilavand F, Saki R, Mirzaei SZ, Lashgarian HE, Karkhane M, Marzban A (2021) Green synthesis of zinc nanoparticles using aqueous extract of Magnoliae officinalis and assessment of its bioactivity potentials. Biointerface Res Appl Chem 11(1):7765-7774. https://doi.org/10.33263/BRIAC111.77657 774

Gopinath V, Priyadarshini S, Priyadharsshini NM, Pandian K, Velusamy P (2013) Biogenic synthesis of antibacterial silver chloride nanoparticles using leaf extracts of Cissus quadrangularis Linn. Mater Lett 91:224-227. https://doi. org/10.1016/j.matlet.2012.09.102

Hemanth Kumar NK, Andia JD, Manjunatha S, Murali M, Amruthesh KN, Jagannath S (2019) Antimitotic and DNA-binding potential of biosynthesized ZnO-NPs from leaf extract of Justicia wynaadensis (Nees) Heyne-a medicinal herb. Biocatal Agric Biotechnol 18:101024. https://doi.org/10. 1016/j.bcab.2019.101024

Jafari M, Salavati-Niasari M, Sobhani A (2013) Silver selenide nanoparticles: synthesis, characterisation and effect of preparation conditions under ultrasound radiation. Micro Nano Lett 8(9):508-511. https://doi.org/10. 1049/mnl.2013.0444 
Jiang J, Pi J, Cai J (2018) The advancing of zinc oxide nanoparticles for biomedical applications. Bioinorg Chem Appl. https://doi.org/10.1155/2018/ 1062562

Kalishwaralal K, Jeyabharathi S, Sundar K, Muthukumaran A (2016) A novel one-pot green synthesis of selenium nanoparticles and evaluation of its toxicity in zebrafish embryos. Artif Cells Nanomed Biotechnol 44(2):471-477

Kanchi S, Inamuddin Khan A (2020) Biogenic synthesis of selenium nanoparticles with edible mushroom extract: evaluation of cytotoxicity on prostate cancer cell lines and their antioxidant, and antibacterial activity. Biointerface Res Appl Chem 10(6):6629-6639. https://doi.org/10.33263/ BRIAC106.66296639

Kanipandian N, Thirumurugan R (2014) A feasible approach to phyto-mediated synthesis of silver nanoparticles using industrial crop Gossypium hirsutum (cotton) extract as stabilizing agent and assessment of its in vitro biomedical potential. Ind Crops Prod 55:1-10. https://doi.org/10. 1016/j.indcrop.2014.01.042

Kanipandian N, Kannan S, Ramesh R, Subramanian P, Thirumurugan R (2014) Characterization, antioxidant and cytotoxicity evaluation of green synthesized silver nanoparticles using Cleistanthus collinus extract as surface modifier. Mater Res Bull 49:494-502. https://doi.org/10.1016/j.materresbu 1.2013.09.016

Liu Y-T, Gong P-H, Xiao F-Q, Shao S, Zhao D-Q, Yan M-M et al (2018) Chemical constituents and antioxidant, anti-inflammatory and anti-tumor activities of Melilotus officinalis (linn.) pall. Molecules 23(2):271. https://doi.org/10. 3390/molecules23020271

Loeschner K, Hadrup N, Qvortrup K, Larsen A, Gao X, Vogel U et al (2011) Distribution of silver in rats following 28 days of repeated oral exposure to silver nanoparticles or silver acetate. Part Fibre Toxicol 8(1):18. https:// doi.org/10.1186/1743-8977-8-18

Lu Y, Qiu Y, Cai K, Ding Y, Wang M, Jiang C et al (2020) Ultrahigh power factor and flexible silver selenide-based composite film for thermoelectric devices. Energy Environ Sci 13(4):1240-1249. https://doi.org/10.1039/ C9EE01609K

Marslin G, Siram K, Maqbool Q, Selvakesavan RK, Kruszka D, Kachlicki P et al (2018) Secondary metabolites in the green synthesis of metallic nanoparticles. Mater Res Bull 11(6):940. https://doi.org/10.3390/ma11060940

Martinez-Nuñez C, Cortez-Valadez M, Delgado-Beleño Y, Hurtado RB, Alvarez RA, Rocha-Rocha O et al (2016) Radial breathing modes in silver selenide quantum dots. Mater Lett 167:135-140

Martinez-Nuñez C, Cortez-Valadez M, Delgado-Beleño Y, Flores-López N, Román-Zamorano J, Flores-Valenzuela J et al (2017) In situ surfaceenhanced Raman spectroscopy effect in zeolite due to $\mathrm{Ag}_{2} \mathrm{Se}$ quantum dots. J Nanopart Res 19(2):31

Mirzaei SZ, Ahmadi Somaghian S, Lashgarian HE, Karkhane M, Cheraghipour K, Marzban A (2020) Phyco-fabrication of bimetallic nanoparticles (zincselenium) using aqueous extract of Gracilaria corticata and its biological activity potentials. Ceram Int 48(4):5580-5586. https://doi.org/10.1016/j. ceramint.2020.10.142

Mladenović K, Muruzović M, Stefanović O, Vasić S, Čomić R (2016) Antimicrobial, antioxidant and antibiofilm activity of extracts of Melilotus officinalis (L.) Pall. J Anim Plant Sci 26(5):1436-1444

Qayyum S, Khan AU (2016) Nanoparticles vs. biofilms: a battle against another paradigm of antibiotic resistance. MedChemComm 7(8):1479-1498. https://doi.org/10.1039/C6MD00124F

Reyes-Torres MA, Mendoza-Mendoza E, Miranda-Hernández ÁM, Pérez-Díaz MA, López-Carrizales M, Peralta-Rodríguez RD et al (2019) Synthesis of $\mathrm{CuO}$ and $\mathrm{ZnO}$ nanoparticles by a novel green route: antimicrobial activity, cytotoxic effects and their synergism with ampicillin. Ceram Int 45(18, Part A):24461-24468. https://doi.org/10.1016/j.ceramint.2019.08.171

Shah S, Gaikwad S, Nagar S, Kulshrestha S, Vaidya V, Nawani N et al (2019) Biofilm inhibition and anti-quorum sensing activity of phytosynthesized silver nanoparticles against the nosocomial pathogen Pseudomonas aeruginosa. Biofouling 35(1):34-49. https://doi.org/10.1080/08927014 2018.1563686

Shaikh S, Nazam N, Rizvi SMD, Ahmad K, Baig MH, Lee EJ et al (2019) Mechanistic insights into the antimicrobial actions of metallic nanoparticles and their implications for multidrug resistance. Int J Mol Sci 20(10):2468. https://doi.org/10.3390/ijms20102468

Sibiya P, Moloto M (2016) Starch-capped silver selenide nanoparticles: effect of capping agent concentration and extraction time on size. Asian J Chem 28(6):1315. https://doi.org/10.14233/ajchem.2016.19672

Sibiya NP, Moloto MJ (2017) Shape control of silver selenide nanoparticles using green capping molecules. Green Process Synth 6(2):183-188. https://doi.org/10.1515/gps-2016-0057

Sidorova D, Lipasova V, Nadtochenko V, Baranchikov A, Astafiev A, Svergunenko S et al (2018) Synthesis of silver nanoparticles with the use of herbaceous plant extracts and effect of nanoparticles on bacteria. Appl Biochem Microbiol 54(8):816-823. https://doi.org/10.1134/S000368381 8080069

Subhanandaraj T, Raghavan K, Narayanan RAN (2020) Antibacterial and antibiofilm activity of probiotic based silver nanoparticles is a green approach in biomedical applications. Lett Appl NanoBioSci 9(2):988-994. https:// doi.org/10.33263/LIANBS92.988994

Sytu MRC, Camacho DH (2018) Green synthesis of silver nanoparticles (AgNPs) from Lenzites betulina and the potential synergistic effect of AgNP and capping biomolecules in enhancing antioxidant activity. BioNanoScience 8(3):835-844. https://doi.org/10.1007/s12668-018-0548-x

Tripathy A, Behera M, Rout AS, Biswal SK, Phule AD (2020) Optical, structural, and antimicrobial study of gold nanoparticles synthesized using an aqueous extract of mimusops elengi raw fruits. Biointerface Res Appl Chem 10(6):7085-7096. https://doi.org/10.33263/BRIAC106.70857096

Vo DQ, Dung DD, Cho S, Kim S (2016) A simple synthesis of Ag 2+ x Se nanoparticles and their thin films for electronic device applications. Korean J Chem Eng 33(1):305-311. https://doi.org/10.1007/s11814-015-0141-8

Vorobyev S, Likhatski M, Romanchenko A, Maksimov N, Zharkov S, Krylov A et al (2018) Colloidal and deposited products of the interaction of tetrachloroauric acid with hydrogen selenide and hydrogen sulfide in aqueous solutions. Minerals 8(11):492. https://doi.org/10.3390/min8110492

Yang Y, Pan D, Zhang Z, Chen T, Xie H, Gao J et al (2018) Ag 2 Se quantum dots for photovoltaic applications and ligand effects on device performance. J Alloys Compounds 766:925-932. https://doi.org/10.1016/j.jallcom.2018. 07.022

\section{Publisher's Note}

Springer Nature remains neutral with regard to jurisdictional claims in published maps and institutional affiliations.

\section{Submit your manuscript to a SpringerOpen ${ }^{\circ}$ journal and benefit from:}

- Convenient online submission

- Rigorous peer review

- Open access: articles freely available online

- High visibility within the field

- Retaining the copyright to your article

Submit your next manuscript at springeropen.com 